\title{
Aprendiendo de los mosaicos forestales comunitarios y de pequeños productores para apoyar medios de vida sostenibles en la Amazonia
}

\begin{abstract}
Introducción
En la Amazonia peruana y ecuatoriana, millones de hectáreas de bosques tropicales son propiedad o están ocupados o controlados por pueblos indígenas o pequeños propietarios que dependen de los bosques para su sustento. Las decisiones que estos grupos toman relativas al manejo forestal están influenciadas por diversos factores pero uno de los que no se entiende a cabalidad es el papel que desempeñan los derechos de propiedad. Los derechos de propiedad pueden ser formales, informales o consuetudinarios, compartidos o individuales, en disputa o inseguros. En conjunto, afectan el uso de los bosques y la participación en los mercados.
\end{abstract}

El diseño de políticas forestales y estrategias de manejo forestal que respondan a las necesidades de los pequeños propietarios y las comunidades debería realizarse en base a un entendimiento más completo de los sistemas endógenos de manejo forestal que sustentan los medios de vida, de cómo y por qué estos sistemas han cambiado con el tiempo y cómo se vinculan a los mercados de productos forestales. La finalidad de esta investigación aplicada, que cuenta con financiamiento de la Agencia de los Estados Unidos para el Desarrollo Internacional (USAID) es realizar, durante dos años, un análisis comparativo que permita ayudar en el diseño de estrategias que apoyen el manejo forestal sostenible y la conservación.

\section{La importancia de los pequeños propietarios y los bosques comunitarios}

Cada vez más, las poblaciones rurales en la Amazonia y sus bosques están respondiendo o se sienten presionadas por fuerzas de mercado y dinámicas de frontera que promueven la conversión de los bosques. En este sentido, cabe preguntarnos: ¿Qué factores producen este cambio en el uso de suelo? ¿Qué opciones de medios de vida sostenibles existen que beneficiarían tanto a los bosques como a las poblaciones locales?

Por lo general, las fronteras forestales albergan una diversidad de actores que tienen diferentes intereses en los bosques. Las comunidades indígenas usualmente tienen importantes superficies forestales, relativamente intactas, que manejan en forma comunal con fines de subsistencia. En el caso de los colonos, es más común que tengan parcelas individuales que convierten para usos agrícolas o en pastizales. Sin embargo, los pueblos indígenas también tienen tierras individuales, convierten el bosque para otros usos y venden madera. De igual forma, muchos colonos mantienen reservas forestales, reforestan $y$, en ocasiones, unen fuerzas para manejar los bosques en cooperativas y asociaciones. Además de los actores locales, existen otros actores importantes como las empresas madereras, mineras y petroleras. Sus demandas o derechos formales coinciden con las de los pequeños propietarios y pueblos indígenas. Por su parte, los actores en el campo de desarrollo han construido redes camineras y facilitado el acceso al mercado mientras que los fiscalizadores del gobierno tratan de controlar la conducta y pueden influenciarla de maneras inesperadas, imponiendo nuevos arreglos institucionales sobre los existentes, obligando a las comunidades a participar en el mercado informal o creando incentivos perversos que pueden generar deforestación y degradación.

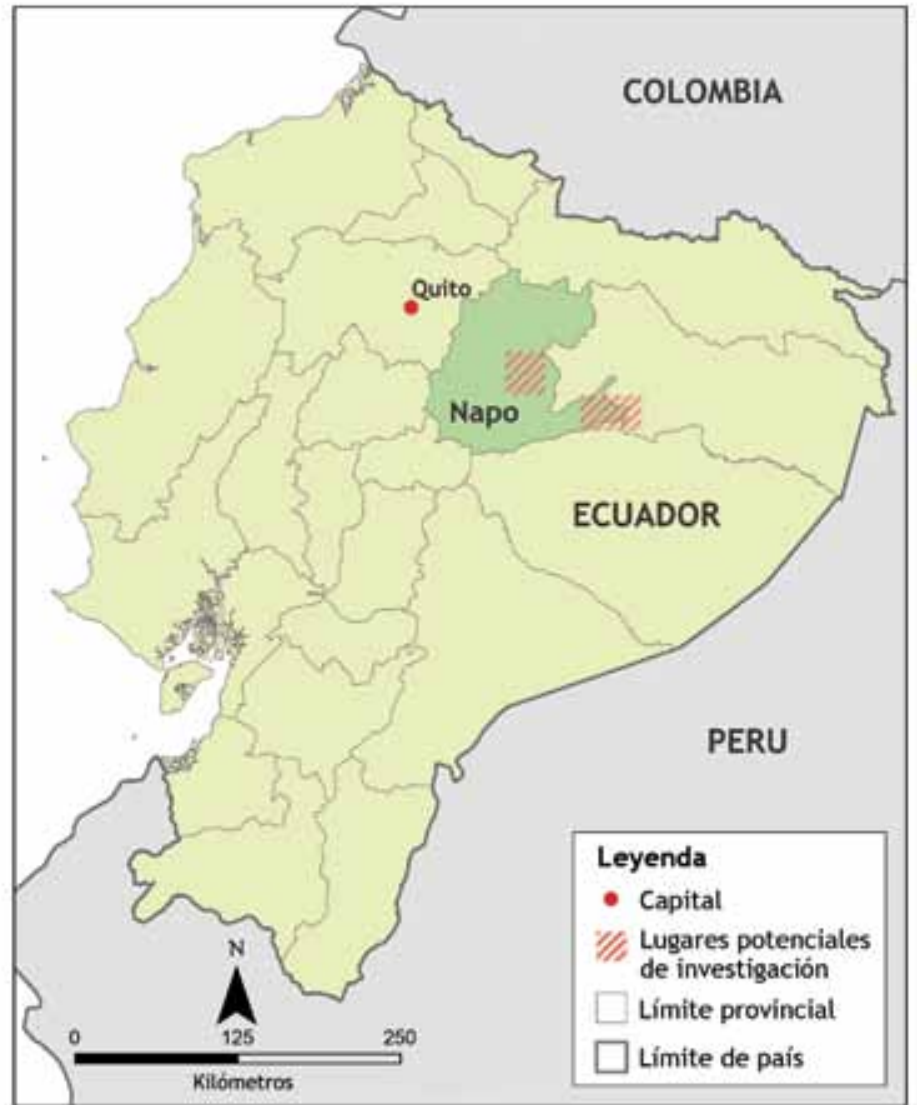

Lugares de investigación en Ecuador

Este estudio analiza la diversidad de actores e impactos de los procesos de políticas a nivel del paisaje local para ilustrar los motores principales de las decisiones de manejo forestal local y de la transformación de los bosques e identificar lecciones que permitan mejorar el desarrollo regional, los medios de vida rurales y el manejo forestal.

La investigación en Ecuador tendrá lugar en la provincia de Napo mientras que en Perú, en los departamentos de Huánuco y Ucayali. En ambos países se elegirán dos lugares de investigación -que cubran áreas de aproximadamente 80,000 ha- para incluir una diversidad de actores, usos forestales y regímenes de derechos de propiedad. En cada país, los lugares elegidos incluirán fronteras forestales tanto nuevas como antiguas (véanse mapas).

\section{Objetivos de la investigación}

Este proyecto tiene como objetivo general identificar los factores que configuran y limitan los sistemas endógenos de manejo forestal de los pequeños propietarios y las comunidades de la Amazonia para definir mejores programas y estrategias que apoyen los medios de vida rurales, fortalezcan la gobernanza local y promuevan la sostenibilidad forestal. 
La investigación tiene cuatro objetivos específicos:

- Definir el mosaico de actores, regímenes de derechos de propiedad, formales e informales, y sistemas de manejo forestal a escala de paisaje en dos lugares de investigación en cada país;

- Examinar las relaciones entre los mosaicos de manejo forestal comunitario y de los pequeños productores e identificar los motores de cambio de uso de suelo con el tiempo;

- Analizar las estrategias y prácticas utilizadas por los administradores del bosque para vincularse con importantes mercados de bienes forestales así como la importancia de los productos forestales para los medios de vida de los hogares;

- Promover el diseño de modelos apropiados que apoyen políticas, leyes y regulaciones forestales y de manejo forestal sostenible, enfatizando las prácticas forestales y las instituciones de gobernanza endógenas.

\section{Actividades del proyecto y resultados esperados}

Esta investigación busca aumentar el entendimiento de los sistemas de manejo forestal comunitario y de los pequeños propietarios en paisajes amazónicos; analizar el impacto de los marcos regulatorios y de políticas; explorar los vínculos locales con los mercados de productos forestales y fortalecer la capacidad de adaptación de los usuarios locales de recursos. El proyecto tiene dos componentes: El primero analiza los cambios en el uso de suelo, los regímenes de derechos de propiedad y la seguridad de la tenencia y los sistemas de manejo forestal de diversos actores, pequeños propietarios e indígenas, a escala de paisaje. Explora las percepciones y planes de los usuarios forestales, identifica las presiones y oportunidades que configuran los sistemas endógenos de manejo tradicional y analiza el papel que desempeñan en el mantenimiento y la conversión de la cobertura forestal. El segundo componente explora los mercados para los productos forestales vendidos por los pequeños propietarios y las comunidades, analizando las estrategias usadas para manejar y comercializar estos productos, los beneficios que resultan de este comercio y cómo estos sistemas se ven afectados por las políticas y los marcos regulatorios.

\section{Papel de los socios}

CIFOR estará a cargo de la coordinación del proyecto, supervisión de la investigación y brindará apoyo a la investigación realizada por los socios locales, en especial el Grupo Faro en Ecuador y el Instituto del Bien Común en Perú. CIFOR también coordinará talleres de capacitación y de intercambio de información en ambos países. La investigación se realizará en colaboración y consulta con las oficinas de USAID en Ecuador y con el Proyecto Costas y Bosques y, en Perú, con el Programa de Manejo Ambiental y Gobernabilidad Forestal y con consorcios apoyados por la Iniciativa para la Conservación de la Amazonia Andina (ICAA) que trabajan en regiones seleccionadas para construir sinergias donde hay coincidencia de intereses. El proyecto también participará en los procesos existentes de planificación a nivel provincial y municipal.

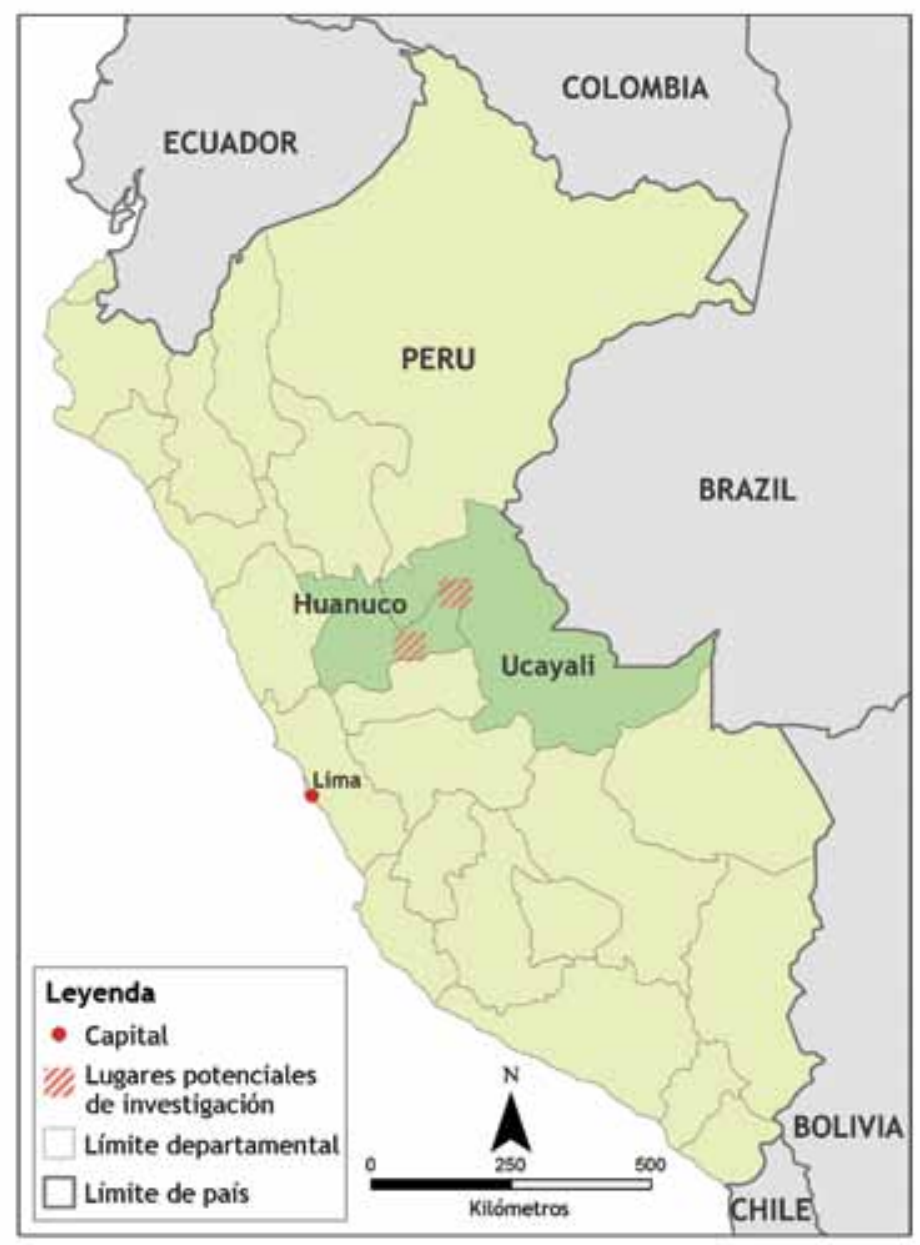

Lugares de investigación en Perú

\section{Resultados esperados e impactos}

El conocimiento generado por este estudio llenará un vacío en la investigación de ambos países. Permitirá un mejor entendimiento de los factores que afectan el uso forestal y la conducta de manejo de los pequeños propietarios y las comunidades, incluyendo los arreglos de tenencia de tierra, los marcos regulatorios forestales $y$ las condiciones de mercado y, por lo tanto, comprender cómo los actores locales deciden mantener la cobertura forestal, degradar el bosque o deforestar a través del clareo.

La investigación tiene como objetivo aportar recomendaciones para las reformas legales y de política y los procesos de gobernanza forestal a nivel nacional y subnacional en los dos países así como para intervenciones de proyecto que apoyen la forestería sostenible. Este análisis también apoyara el diseño de programas REDD+en cada país y en la región.

\section{USAID

